DOI: $10.14451 / 2.129 .9$

\title{
УЛЬТРААКТИВНОЕ ДЕЙСТВИЕ УГОЛОВНОГО ЗАКОНА
}

\author{
(C) 2019 Караева Лора Хазбатровна \\ кандидат юридических наук, доцент кафедры уголовного права и процесса \\ Северо-Осетинский государственный университет имени К.Л. Хетагурова, Россия, Владикавказ \\ E-mail: m.dzagoeva1971@yandex.ru \\ (c) 2019 Кочиева Олеся Ахсаровна \\ Председатель Верховного Суда \\ Республика Южная Осетия, Цхинвал \\ E-mail: 71dz@mail.ru
}

В статье рассматриваются тенденции уголовно-правового законотворчества, затрагивающие положение уголовного закона о его действии во времени и анализируется ультраактивный принцип действия Уголовного Кодекса Российской Федерации во времени.

Ключевые слова: уголовный закон, действие уголовного закона во времени, принципы действия, преступность и наказуемость деяния.

Большинство противоречий, вызванных стремлением толкования принципа преступности и наказуемости нарушения по закону времени его осуществления, даже в случае, если закон уже не действует, связано с тем, что его действие рассматривается в соответствии с формально-логическими нормами, действующими только в отношении «моментальных снимков» с реальности. Это обусловливает веру обывательского рассудка в то, что есть правовой мир, представляющий собой всеобъемлющий комплекс непрерывно работающих (каждый в своем времени) правовых норм, рамки практического применения которых связаны исключительно с ограниченностью жизни человека или генерации, живущих в период действия данного конкретного законодательства. Однако данный факт не мешает применять законодательство и за названными рамками. Так, теоретически вполне оправданным является тот факт, что в 1993 году Генеральная прокуратура РФ возбудила уголовное дело в отношении обстоятельств смерти лиц, представлявших российский императорский дом и людей из их окружения в 1918-1919 годах. Также вполне правомерным было бы возбуждение уголовного дела и по факту смерти Павла I в 1801 г., сына Ивана Грозного в 1582 г., Бориса и Глеба в 1015 г., князя Игоря в 945 г. и пр. Но при этом важно установить, что с тех пор и по сегодняшний день, хоть и в разном виде, имеется норма уголовного права, устанавливающая ответственность за подобные преступления. Также эта норма должна воспроизводить важную для нее самоотносимость. Для этого потребовалось бы пересмотреть все существовавшие в месте их осуществления и поэтапно приходящие на смену друг другу правовые акты, в рамках которых применяется данная норма. На их основе должна быть выведена синтезировать темпоральная коллизионная норма.

Противоречивость ситуации, обусловленная действием нормы свыше положенного для нее срока, всегда представляла краеугольный камень в уголовно-правовой теории. Действительно, если действие закона останавливается после того, как он утрачивает силу, как можно его применять? Людей, по большому счету, осуждают с точки зрения избывшего себя закона, то есть с точки зрения нежизни. Проистекающие из этого противоестественные обстоятельства способствуют противоестественному пониманию правовой действительности. Подобную иллюзию рассматривают в качестве истины, якобы освобождающей людей от единого закона жизни и смерти. Несоответствие логики абсурда логике здравого рассудка, которая все же возвышается над человечеством, стремятся разрешить, используя юридическую казуистику. К примеру, А.А. Тилле в соответствии с тем, что существуют вышедшие из действия законы, заключает, что между терминами «утрата силы» и «прекращение действия» нельзя ставить знак равенства [1, c.15]. Я.М. Брайнин говорил о необходимости проведения границы между вступлением закона в силу и его фактическим действием [2, с. 132]. Противоречие может присутствовать лишь в 
дескрипции фактов, но не в них самих. При этом разрешение данного парадокса с сохранением логической последовательности в умозаключениях на уровне правовой догмы не может иметь место. Стремление толковать действие закона post mortem похожи на стремление вернуть к жизни мертвого. Однако в действительности невозможное не станет возможным. Закон - это закон, и период его действия от момента появления до момента утраты силы всегда характеризуется строгими временными рамками. По-другому дело обстоит с нормой. Ее нельзя рассматривать в качестве безначального и бесконечного идеала, однако ей свойственны другие календарные точки отсчета по сравнению с законом, который ее обеспечивает.

К примеру, причинение смерти пожилым и инцест выступали в качестве моральных норм до момента возникновения первых примитивных запретов на агрессивное поведение и действия и сексуального характера в первичных общественных формированиях. Сейчас термин «преступление» является словесным обликом для большого количества различных нарушений, обладающих такой центробежной силой, что одно их перечисление может «расщепить» всякое социальное понятие. Следует ли из этого, что «преступное» является искусственным явлением, то есть что «кто-то» использует данное понятие? Разумеется, нет. Уникальность преступности является только небольшим эпизодом жизнедеятельности общества, на который влияют социальное место и время. После того как была утверждена частная собственность на движимость, случаи хищений продолжились. Для хозяйственной преступности необходимы развитые экономические отношения. Преступность, подразумевающая деяния против окружающей среды, затрагивает индустриальное общество. Преступления компьютерной направленности затрагивают информационное сообщество.

В данном исследовании мы не будем говорить о правильности термина «абсолютные преступления», так как едва ли кто-то сможет точно сказать, чем является преступность: преходящим феноменом или постоянным пороком человечества. Суть в том, что, невзирая на огромную многоплановость общественного уклада, находящегося под защитой уголовного права во все времена, всегда были преступления, которые невозможно было не запрещать, в связи с чем появление подобных норм абсолютного характера отстает на несколько веков от момен- та появления современного законодательства, представляющего собой только относительную, определяемую временными рамками форму его бытия. Из древности словно переходят в реальность люди и факты, неся в себе древние уголовно-правовые памятники и их установления, призрачные отражения которых до сих пор хранит в себе нынешний закон. Таким образом, тем, где происходит отмирание одного закона, начинается жизнь нового. При этом всегда существует уголовно-правовая норма. Со временем отбрасывая разнообразные пережитки, сущность закона обретает новую форму жизни, способствуя такому процессу, как уголовно-правовая преемственность.

Так как уголовному праву свойственна позитивно-ретроспективная сущность, действие его установлений распространяется как на вероятные ситуации в перспективе, так и на имевшие место факты былого. Вероятное преступное деяние является превентируемым феноменом, благодаря которому норма начинает действовать в перспективно-регулятивном направлении. Имеющее место преступное деяние является свершившимся действием, заставляющим норму работать в ретроспективно-охранительном режиме. При этом прошлое, событием в котором стало преступное деяние, может быть более далеким по сравнению с моментом реализации защитного потенциала нормы, которая за этот период была включена в новое законодательство. Это законодательство не действует в отношении такого преступного деяния, однако это действие имеется у нормы в той ее законной форме, в какой она имелась на момент осуществления преступного деяния. Ее может удержать во времени новое законодательство. Это проистекает из формулировки, согласно которой преступность и наказуемость преступления устанавливаются в уголовном законодательстве, актуальном на момент его осуществления. Эта норма не просто задает рамки использования новых установлений, но и способна продлить срок жизни старых. Таким образом реализуется темпоральная «привязка» переходных коллизионных норм [3, с. 30].

Итак, ультраактивного действия ранее действовавшего закона можно достичь за счет того, что, будучи местом установления норм уголовного права, он оказывается поддерживаемым новым законодательством. С того момента как вводится в силу новый закон, предыдущий утрачивает свою силу в отношении будущего только позитивно. При этом не происходит утрата его 
защитной возможности по отношению к деяниям, осуществленным в прошлом. Однако подобная власть над прошлым сохраняется лишь в той мере, в какой ее может поддержать новый закон, с идентичными позитивными установлениями в настоящем, так как любое событие в прошлом подразумевает наличие конкретной современной перспективы. Иными словами, новый закон может пролонгировать ретроспективные установления ранее действовавшего закона старого только в той степени, в которой ранее обеспечивающие их позитивные требования закрепляются и в нем. Подобное толкование вопроса предлагалось и Рипером, который обратил внимание на то, что продолжительные юридические отношения строятся на основе крепкой арматуры былого закона. Если его отменят, нужно будет установить, что рушится, а что остается жизнь под действием вновь принимаемых законов. Вопрос законодательной коллизии весьма сложен. Так или иначе, его можно решить, лишь пройдя долгий путь дискуссий и противоречий, что до сих пор становится причиной жертв уголовного законодательства [1, с. 38].

Чтобы этого избежать, следует помнить, что закон является только формой жизни нормы права. При утрате ее содержания (при декриминализации преступления), пропадает потребность и в форме. При сохранении содержания отмена одних и закрепление других законов способны только провести временную границу, в рамках которой норма уголовного права «скидывает» с себя одну форму и облекается в новую. Причем ее можно создать по тому «образу и подобию», в котором она присутствовала в прежнем законе. В этом случае ее необходимо только сопоставить с периодом осуществления преступного деяния. В случае, когда норма является в новом облике с утратой ряда репрессивных свойств, то определенные детали прежних «одежд» не требуются и в новом законе [4, с. 195]. Укрепленную же новыми законами ответственность, наоборот, невозможно «прикрепить» к устаревшим позитивным требованиям, у кото- рых имелись собственные соответствовавшие им ретроспективные стимулы, которые должны быть реализованы. При этом следует отметить, что на основании старого закона ответственность можно возлагать только при условии, что новый закон сохраняет необходимые позитивные веления. С этой точки зрения использование закона времени суда представляет собой правило, аналогичное использованию закона времени осуществления преступного посягательства. Одно без другого не существует, потому что осуждение на основании закона времени посягательства не просто отражает объективные, произошедшие когда-то события, но и выражает правоотношения в настоящем.

Итак, традиционная формальная логика как компонент догмы права способна зафиксировать в настоящем движении права лишь миг стабильности и дискретности. При этом в ней не происходит отражение его изменения и формирования.

Концепция действия закона во времени, истолкованная с точки зрения формалистического подхода, коррелирует с многочисленными конечными законами по существу точно так же, как со всей бесконечностью законов, что всегда приводит к формально-логическим контрадикциям. Между тем при образовании множества всех порядковых законов образуется порядковый тип коллизионных норм, которых еще не было среди всех порядковых законов, существовавших до образования этого множества.

Действительно же «мертвой» норма уголовного права становится лишь тогда, когда новый закон декриминализирует предусматриваемое ею деяние. Если еще более поздний закон вновь восстановит его преступность, существовавшая прежде уголовно-правовая норма навсегда утрачивает юридическое значение, ибо нить ее жизни, передаваемой по эстафете от закона к закону, оборвалась, а отсчет жизни другой нормы, даже если она идентична по форме прежней, начинается заново.

\section{Библиографический список}

1. Тилле А.А. Время, пространство, закон. Москва.1965.

2. Брайнин Я.М. Уголовный закон и его применение. Москва.1967.

3. Степенко A.B. Обратная сила и действие уголовного закона во времени: теория и практика // Российский следователь. 2016. № 18. С. 30-32.

4. Тотикова Э.Р., Караева Л.Х. К вопросу о принципах уголовно-правового воздействия, определяющие построение и применение системы уголовно-правовых санкций. Молодежный научный форум: общественные и экономические науки. 2016. № 9 (38). С. 194-198. 